\title{
Mycoplasma Bovis; A Neglected Pathogen in Nigeria- A Mini Review
}

\author{
Francis Markus Isa* \\ Department of Veterinary Microbiology, Nigeria
}

Submission: September 19, 2017; Published: October 17, 2017

*Corresponding author: Francis Markus Isa, Department of Veterinary Microbiology, Faculty of Veterinary Medicine, Ahmadu Bello University Zaria, Nigeria, Tel: +2348067026690; Email: markfrancis4u@gmail.com

\begin{abstract}
Mycoplasma bovis (M. bovis) is the second most pathogenic bovine mycoplasmas known worldwide. It is associated with various diseases in cattle including calf pneumonia, mastitis, arthritis, otitis media, kerato conjunctivitis and genital disorders. Few antimicrobials like tulathromycin, florfenicol, fluoroquinolones and gamithromycin are currently approved for treatment of $M$. bovis infection worldwide. Antibiotic treatment must be instituted early in the course of the disease, and pain relief should be provided for sick cows and calves. Vaccines have been reported to be available against the infection, but have not been proved protective. Early detection of disease, improved husbandry conditions and treatment with effective antimicrobial are currently the best approach in the control of the disease. Mycoplasma bovis infection being a most important emerging disease of cattle is new and poorly understood among cattle owners and field veterinarians in Nigeria. Research to establish the molecular basis and distribution of the disease in Nigeria is recommended.
\end{abstract}

Keywords: Cattle; Disease; Mycoplasma bovis; Nigeria

\section{Introduction}

Mycoplasma bovis is the second most pathogenic mycoplasma after Mycoplasma mycoides subspecies mycoides the causative agent of contagious bovine pleuropneumonia [1]. It was first definitively identified in the USA in 1961 from a cow with mastitis, although clinical signs associated with the organism were described beforehand [2]. It is now recognized as a worldwide pathogen of intensively farmed cattle and in recent years has emerged as an important cause of infection in young dairy calves in North America and Europe [3]. A member of the wall-less bacterium belongs to the Class Mollicutes, Order Mycoplasmatales, Family Mycoplasmataceae, and the Genus Mycoplasma [4] and is among the smallest and simplest freeliving micro-organisms capable of self-replication [5].

The organism causes bovine mycoplasmosis, an infection that leads to a variety of clinical manifestations mostly of chronic nature, including bronchopneumonia [2], otitis media [6], mastitis [7], genital disorders [8], arthritis [9], meningitis [10] and kerato conjunctivitis [11]. Mycoplasma bovis can affect a large variety of tissues and organs and can also be isolated from apparently healthy cattle [12]. Several reports have suggested that mycoplasmas are frequently present in the cattle population, causing disease in conditions of impaired immune response due to stress of transportation, adverse weather condition and impaired feeding $[13,14]$. It adversely affects growth rates resulting in increased cost of production and additional treatment cost, resulting in large economic losses to the cattle industry [15]. The organism is considered to be one of the major emerging pathogens of cattle in industrialized countries threatening livestock production [16]. Elimination of M. bovis is difficult and treatment with antimicrobials is unsuccessful unless animals are treated early in the course of disease [17]. There are no vaccines available commercially against $M$. bovis infection, although the use of auto genus vaccines has shown some success [18]. It is important to effectively target antimicrobial treatment to ensure prudent use of antimicrobials and to reduce the development of antimicrobial resistance [17].

Currently few reports are available on $M$. bovis infection in Nigeria despite the prevalent nature of the organism as reported by these authors [19-23]. On this background, this overview of the infection was presented. The following aspects are discussed:
a) Epidemiology,
b) Clinical signs,
c) Diagnosis,
d) Treatment, 
e) Control and

f) Information about the infection in Nigeria.

4. Epidemiology

Mycoplasma bovis is well adapted to colonization of mucosal surfaces, where it can persist without causing clinical disease. The upper respiratory tract (URT) mucosa is the primary site of $M$. bovis colonization in cattle following URT exposure [24]. After intra mammary exposure, the mammary gland appears to be the major site of colonization [25]. Irrespective of the route of exposure, M. bovis can be isolated from numerous body sites during early infection, particularly the URT, mammary gland, conjunctiva and urogenital tract [26]. Mycoplasmemia during $M$. bovis infection has earlier been documented $[24,25]$. The URT mucosa and the mammary gland appear to be the most important sites of persistence and shedding of the organism [26]. Although many cattle shed M. bovis for a few months or less, some cattle can shed the organism sporadically for many months or years $[26,27]$. The factors responsible for sporadic shedding have not been determined. However, it has been reported that cattle with clinical disease usually shed large numbers of $M$. bovis [1]. Stressful conditions such as transportation, comingling, entry into a feedlot, and cold stress are associated with increased rates of nasal shedding of M. bovis [15]. Chronic asymptomatic infection with intermittent shedding of $M$. bovis appears critical to the epidemiology of infection, especially the maintenance of the agent within a herd and exposure of naive populations [1].

\section{Clinical Signs}

Mycoplasma bovis infection is multi factorial and can manifests itself in any/or combination of the following clinical signs.

\section{Pneumonia}

Mycoplasma bovis-associated pneumonia can be manifested in any cattle in a herd/or farm irrespective of age [2]. Clinical signs are imprecise and include fever, hyperpnoea, dyspnoea, and decreased appetite, with or without nasal discharge and coughing [2]. The severity of calf pneumonia can be further compounded by animal husbandry, the environment, low effectiveness of many antimicrobials, and unknown efficacy of vaccines $[18,28]$. Mycoplasma pneumonia can be accompanied by cases of otitis media, arthritis, or both, in the same animal or in other animals in the farm/herd. Chronic pneumonia and polyarthritis syndrome (CPPS) occur when animals develop polyarthritis in association with chronic pneumonia, and do occur in beef cattle after some weeks of entry into feedlot [1].

\section{Mastitis}

The herd presentation of mycoplasma mastitis varies from endemic subclinical disease to severe clinical mastitis outbreak [29]. Many infections are subclinical, and few numbers of sub clinically infected cows have a marked decrease in somatic cell count or reduced milk production. Cows of any age or stage of lactation are affected [25]. When the disease is clinical, signs are nonspecific and typically more than one quarter is affected. There is a drastic decline in milk production and signs of systemic illness are relatively mild [29]. The mammary gland might be distended but is not usually painful. Secretions vary from mildly abnormal to gritty or purulent, and are sometimes brownish in color. A history of mastitis that is resistant to treatment with antimicrobials is common, and clinical disease can persist for several weeks [1,29]. Arthritis, synovitis, joint effusion or respiratory disease in mastitic or nonmastitic cows can accompany $M$. bovis mastitis [1,30].

\section{Otitis media}

Mycoplasma bovis-associated otitis media occurs in dairy and beef calves as enzootic disease or as outbreaks, and also occurs sporadically in feedlot cattle. In early or mild cases calves remain attentive with a good appetite, but as disease progresses they become febrile and anoraexic. Clinical signs occur as a result of ear pain and facial nerve deficits, especially ear droop and ptosis [31,32]. Ear pain is evidenced by head shaking and scratching or rubbing ears. Epiphora and exposure keratitis can develop secondary to eyelid paresis. Clinical signs can be unilateral or bilateral, and purulent aural discharge can be present if the tympanic membrane has ruptured [1]. Concurrent cases of pneumonia, arthritis, or both are common. Otitis interna and vestibulocochlear nerve deficits can occur as result. Head tilt is the most common clinical sign, but severely affected animals can exhibit nystagmus, circling, falling, or drifting toward the side of the lesion and vestibular ataxia [33]. In advanced otitis mediainterna, meningitis can develop. Spontaneous regurgitation, loss of pharyngeal tone, and dysphagia has also been reported and are indicative of glossopharyngeal nerve dysfunction with or without vagal nerve dysfunction [1].

\section{Arthritis, synovitis and periarticular infection}

Mycoplasma bovis-induced arthritis is supposed to be a consequence of mycoplasmemia [1]. Arthritis was preceded by mycoplasmemia in one calf that was inoculated intratracheally with $M$. bovis [25]. Infections of other body systems that occasionally accompany polyarthritis are also likely to be a consequence of mycoplasmemia [34]. Clinical cases of $M$. bovisinduced arthritis in dairy calves tend to be sporadic and are typically accompanied by respiratory disease within the herd and often within the same animal [34]. Clinical signs are typical of septic arthritis with affected joints being painful and swollen, and calves display varying degrees of lameness and may be febrile in the acute stage of infection [35]. Cattle of any age can be affected by $M$. bovis arthritis [30]. Chronic Pneumonia and Polyarthritis Syndrome (CPPS) have been described in feedlot cattle [9]. Clinical signs are typical of septic arthritis, including acute non-weight bearing lameness with joint swelling, pain, and heat on palpation. The animal might be febrile and anorectic. Involvement of tendon sheaths and periarticular soft tissues is common. Large rotator joints (hip, stifle, hock, shoulder, elbow, 
and carpal) are commonly affected, although other joints such as the fetlock or even the atlantooccipital joint can be involved. Poor response to treatment is a common feature [30].

\section{Kerato conjunctivitis}

Mycoplasma bovis can be isolated from the conjunctiva of healthy and diseased cattle [11,25], although M. bovis-associated ocular disease is considered uncommon [36]. However, there are several reports of outbreaks of kerato conjunctivitis involving M. bovis alone, or in mixed infections with Mycoplasma bovoculi $[11,37]$. An outbreak of severe kerato conjunctivitis, from which $M$. bovis was the only consistently isolated pathogen, was reported in a group of 20 calves. Clinical signs included mucopurulent ocular discharge, severe eyelid and conjunctival swelling, and corneal oedema and ulceration which can resolve within 2 weeks [38]. In a report by Alberti et al., [11], an outbreak of $M$. bovis-associated kerato conjunctivitis in beef calves in Italy was followed by cases of pneumonia and arthritis.

\section{Meningitis}

Mycoplasma bovis infection can cause meningitis in calves which can sometimes be difficult to identify, as calves may just appear to have fevers and be depressed. Signs of apparent neck pain and abnormal eye movements may also be evident [39]. Meningitis can also occur as a complication of mycoplasma otitis media-interna. Mycoplasma bovis has also been isolated from the cerebral ventricles of young calves with clinical signs of meningitis in conjunction with severe arthritis, suggesting disseminated septic disease [1].

\section{Genital Disorders}

In isolated and predominantly experimental cases, Mycoplasma bovis has been associated with genital infections such as abortion in cows and seminal vesiculitis in bulls. However, there is little facts to support an important role for $M$. bovis in naturally occurring bovine reproductive disease [1].

\section{Diagnosis}

Rapid and accurate diagnosis of $M$. bovis infections is compromised by the low sensitivity and, in some cases, specificity of the available tests, and subclinical infections and intermittent shedding complicate diagnosis [1]. Various laboratory tests are currently used for the screening, detection and confirmation of the pathogen in cattle. Detection of the M. bovis organism is generally carried out either by a capture enzyme-linked immunosorbent assay (ELISA), or culture isolation using special media, or molecular tests [15]. Serological methods are useful screening tests but of limited use at the early stage of infection as sero-conversion is usually at least two weeks post infection. The isolation and culture of Mycoplasma species requires specialist skills and is not always successful due to multiple mycoplasma infections, or presence of other bacteria $[39,5]$. It has been previously reported that the specificity of serological, culture and some molecular tests may have limitations, and may result in misidentification or inconclusive results $[40,41]$.

\section{Treatment}

The good news about Mycoplasma bovis infection is that unlike other mycoplasma diseases, antimicrobials are recommended for its treatment. Although there is scanty information about pharmacokinetic and pharmacodynamic data on the treatment of $M$. bovis infections [1]. There is no effective therapy of mastitis and only limited success in treatment of respiratory and joint infections caused by $M$. bovis have been reported [2,42]. Two antimicrobials have been approved in the United States for treatment of bovine respiratory disease (BRD) associated with M. bovis. These are tulathromycin (Draxxin, Pfizer Animal Health, New York, NY) and florfenicol (Nuflor Gold, Intervet/Schering-Plough Animal Health, Summit, NJ). Another macrolide, gamithromycin (Zactran Injectable Solution, Merial Canada, Baie d'Urfe, Quebec, Canada), is approved for treatment of $M$. bovis-associated BRD in Canada [1]. However, in countries where fluoroquinolones and spectinomycin do carry appropriate labels, they have been recommended to be the most effective drugs for treatment of $M$. bovis infections [1,43]. Antibiotic treatment must be done early in the course of the disease, and pain relief should be provided for sick cows and calves [44].

For the treatment of $M$. bovis-associated arthritis have an especially poor response to treatment. Aggressive early treatment before the development of extensive tissue necrosis seems most likely to be successful. Fluoroquinolones, tetracyclines, and macrolides tend to have good distribution into joints [45]. Myringotomy with irrigation of the middle ear has been recommended for the treatment of otitis media in calves. There is a report of successful surgical treatment of a calf with M. bovis-associated otitis media-interna in which a bilateral tympanic bulla osteotomy was performed [33].

\section{Prevention and control}

Although vaccines have been reported to be available in developed nations against this infections, but have not proved to be protective $[14,46]$. The best way to prevent Mycoplasma bovis infections is probably to maintain a closed herd or, if that is not possible, to screen and quarantine newly purchased animals. The use of sick boxes for sick cows and good sectioning of different age groups of calves and young animals are very important to prevent outbreaks [44]. Calf health records should be examined where necessary to determine if $M$. bovis-associated diseases such as otitis media have been observed. [1]. Early detection of disease, improved husbandry conditions, and treatment with effective antimicrobial are currently the best approach in the control of the disease [15].

\section{Information about the infection in Nigeria}

Nigeria being a giant of Africa is endowed with abundant livestockresources with estimated cattle population of 19.5 million which make the country number one in livestock production in Africa [47]. The country could not utilize up to $50 \%$ of its dairy and beef industries as compared to developed nations. Diseases 
are regarded as setbacks in actualization of animal production in Nigeria of which Mycoplasma bovis infection is among [48]. This organism has been documented to cause economic impacts in those countries that are certified free from contagious bovine pleura pneumonia [49]. To the best of my knowledge, there are as such few reports available on Mycoplasma bovis infection in Nigeria. Mycoplasma bovis infection being one of the serious economic diseases of cattle has not been given sufficient attention it deserves [50]. Epidemiological studies were conducted in northwestern states of Nigeria $[20,21]$ and northeastern Nigeria $[22,23,48]$, the authors reported M. bovis to be prevalent in their study areas. Ajuwape et al. [20] reported 23.1\% prevalence using biochemical and serological identification on pneumonic lung tissues of cattle; Tambuwal et al. [21] reported 66\% servo prevalence using sera samples of cattle; Egwu et al. [19] reported $1.5 \%$ prevalence using isolation and biochemical identification of apparently normal and pneumonic lungs of sheep and goats. Whereas Francis et al. [49] and Francis et al. [23] reported 2.0\% and $19.5 \%$ respectively using pneumonic lungs and sera samples of cattle.

There are reports of high number of cases of ear infections, arthritis and coughing being encountered on the field/farm more especially in the northern Nigeria which points at $M$. bovis infection, but in most instances such cases are ignored or misdiagnosed (Francis, personal observation). To the practicing veterinarian in the field, once face with such cases, his mind will be directed towards Contagious Bovine Pleuropeumonia (CBPP) which in also presents similar clinical signs and thereby neglecting other causative agents such as M. bovis infection.

\section{Conclusion}

Mycoplasma bovis infection could be a most important emerging disease of cattle and small ruminants has been reported to be a reservoir of the infection in Nigeria. But because the disease seems to be new and poorly understood among cattle owners and field veterinarians, research is therefore needed to establish the molecular basis and distribution of the disease in Nigeria. As at present, a research work is in progress in northeast Nigeria, which aimed to identify and confirm whether pathologic lung lesions encountered in most abattoirs in the region were as a result of CBPP or co-infection with other pathogenic mycoplasmas which $M$. bovis is one of the targets.

\section{References}

1. Maunsell FP, Woolums AR, Francoz D, Rosenbusch RF, Step Dl, et al. (2011) Mycoplasma bovis Infection In Cattle. J Vet Int Med 25(4): 772-783.

2. Caswell Jl, Archambault M (2007) Mycoplasma bovis Pneumonia In Cattle. Anim Hlth Res Rev 8(2): 161-186.

3. Maunsell FP, Donovan GA (2009) Mycoplasma bovis Infections In Young Calves. Vet Clin North Am Food Anim Pract 25(1): 139-177.

4. Razin S, Yogev D, Naot Y (1998) Molecular Biology And Pathogenicity Of Mycoplasmas. Microbiol Mol Biol Rev 62(4): 1094-1156.
5. McAuliffe L, Kokotovic B, Ayling RD, Nicholas RA (2004) Molecular Epidemiological Analysis of Mycoplasma bovis Isolated From The United Kingdom Show Two Genetically Distinct Cluster. J Clin Microbiol 42(10): 4556-4565.

6. Maeda T, Shibahara T, Kimura K, Wada Y, Sato K, et al. (2003) Mycoplasma bovis-Associated Suppurative Otitis Media And Pneumonia In Bull Calves. J Comp Pathol 129(2-3): 100-110.

7. Jasper DE (1994) Mycoplasma and Bovine Mastitis. In: Whitford, HW et al. (Eds.), Mycoplasmosis in Animals: Laboratory Diagnosis. Iowa State University, Ames, USA, pp. 62-67.

8. Hermeyer K, Buchenau I, Thomasmeyer A, Baum B, Spergser J, et al. (2012) Chronic Pneumonia In Calves After Experimental Infection With Mycoplasma bovis Strain 1067: Characterization Of Lung Pathology, Persistence Of Variable Surface Protein Antigens And Local Immune Response. Acta Vet Scand 54:9.

9. Gagea MI, Bateman KG, Shanahan RA, van Dreumel T, McEwen BJ, et al. (2006) Naturally Occurring Mycoplasma bovis-Associated Pneumonia And Polyarthritis In Feedlot Beef Calves. J Vet Diagn Investign 18(1): 29-40.

10. Ayling RD, Nicholas RAJ, Hogg R, Wessels J, Scholes S, et al. (2005) Mycoplasma bovis Isolated From Brain Tissue Of Calves. Vet Rec 156(12): 391-392.

11. Alberti A, Addis MF, Chessa B, Cubeddu T, Profiti M, et al. (2006) Molecular And Antigenic Characterization Of Mycoplasma bovis Strain Causing An Outbreak Of Infectious Keratoconjunctivitis. J Vet Diagn Investign 18(1): 41-51.

12. Burki S, Frey J, Pilo P (2015) Virulence, Persistence And Dissemination of Mycoplasma bovis. Vet Microbiol 179(1-2): 15-22

13. Timsit E, Arcangioli MA, Bareille N, Seegers H, Assié S (2012) Transmission Dynamics of Mycoplasma bovis In Newly Received Beef Bulls At Fattening Operations. J Vet Diagn Invest 24(6): 1172-1176.

14. Aebi M, Van Den Borne BHP, Raemy A, Steiner A, Pilo P, et al. (2015) Mycoplasma bovis Infections In Swiss Dairy Cattle: A Clinical Investigation. Acta Vet Scan 57: 10.

15. Szacawa E, Szymańska-Czerwińska M, Niemczuk K, Dudek K, Bednarek D, et al. (2016): Comparison Of Serological, Molecular And Cultural Diagnostic Methods For The Detection Of Mycoplasma bovis Infections In Cattle. Anim Sci Pap Rep 34(4): 351-359.

16. Nicholas RAJ (2011) Bovine Mycoplasmosis: Silent and Deadly. Vet Rec 168(17): 459-462.

17. Ayling RD, Rosales RS, Barden G, Gosney FL (2014) Changes In Antimicrobial Susceptibility Of Mycoplasma bovis Isolates From Great Britain. Vet Rec 175(19): 486.

18. Nicholas RA, Ayling RD, McAuliffe L (2009) Vaccines for Mycoplasma Diseases in Animals and Man. J Comp Pathol 140(2-3): 85-96.

19. Egwu GO, Nicholas RAJ, Ameh JA, Bashiruddin JB (1996) Contagious Bovine Plueropneumonia: An Update. Vet Bull 66: 875- 888.

20. Ajuwape ATP, Ikheloa J0, Ojo MO, Alaka O0, Adatosoye AJ (2003) Biochemical And Serological Identification Of Mycoplasmas Isolated From Pneumonic Bovine Lungs In Nigeria. Israel J Vet Med Microbiol Parasitol 58: 2-6.

21. Tambuwal FM, Stipkovits L, Egwu GO, Junaidu AU, Abubakar MB, et al. (2011) Enzyme-Linked Immunosorbent Assay (Elisa) Based Detection Of Antibodies To Mycoplasma bovis In Cattle Naturally Infected With Haemoparasites In Institutional Farms In Sokoto State, Nigeria. Current Res J Biol Sci 3(1): 12-16.

22. Francis MI, Ejeh EF, Raji MA, Kazeem HM, Musa JA, et al. (2014) Isolation and Biochemical Identification of Mycoplasma bovis in Cattle Pneumonic Lungs in Adamawa State, Nigeria. Sahel J Vet Sci 13: 1-5. 
23. Francis MI, Raji MA, Kazeem HM, Suleiman MM (2015) Elisa-Based Serological Survey of Mycoplasma bovis in Cattle in Three Local Government Areas in Adamawa State, Nigeria. J Adv Vet Anim Res 2(2): 170-174

24. Nicholas RA, Ayling RD, Stipkovits LP (2002) An Experimental Vaccine For Calf Pneumonia Caused By Mycoplasma bovis: Clinical, Cultural, Serological And Pathological Findings. Vaccine 20(29-30): 3569-3575.

25. Fox LK, Muller FJ, Wedam ML, Schneider CS, Biddle MK (2008) Clinical Mycoplasma bovis Mastitis In Prepubertal Heifers On 2 Dairy Herds. Can Vet J 49(11): 1110-1112.

26. Punyapornwithaya V, Fox LK, Hancock DD, Gay JM, Alldredge JR (2010) Association Between An Outbreak Strain Causing Mycoplasma bovis Mastitis And Its Asymptomatic Carriage In The Herd: A Case Study From Idaho, USA. Prev Vet Med 93(1): 66-70.

27. Biddle MK, Fox LK, Hancock DD (2003) Patterns Of Mycoplasma Shedding In The Milk Of Dairy Cows With Intramammary Mycoplasma Infection. J Am Vet Med Assoc 223(8): 1163-1166.

28. Soehnlen MK (2011) Molecular Characterization And Epidemiology Of Mycoplasma bovis Doctor Of Philosophy Dissertation The Pennsylvania State University, USA, pp: 214.

29. González RN, Wilson DJ (2003) Mycoplasmal Mastitis in Dairy Herds. Vet Clin North American Food Anim Prac, 19(1): 199-221

30. Wilson DJ, Skirpstunas RT, Trujillo JD, Cavender KB, Bagley CV, et al. (2007) Unusual History And Initial Clinical Signs Of Mycoplasma bovis Mastitis And Arthritis In First-Lactation Cows In A Closed Commercial Dairy Herd. J Am Vet Med Assoc 230(10): 1519-1523.

31. Lamm CG, Munson L, Thurmond MC, Barr BC, George LW (2004) Mycoplasma Otitis In California Calves J Vet Diagn Invest 16: 397-402.

32. Francoz D, Fecteau G, Desrochers A, Fortin M (2004) Otitis Media In Dairy Calves: A Retrospective Study Of 15 Cases (1987 To 2002). Can Vet J 45(8): 661-666.

33. Van Biervliet J, Perkins GA, Woodie B, Pelligrini-Massini A, Divers TJ, et al. (2004) Clinical Signs, Computed Tomographic Imaging, And Management Of Chronic Otitis Media/Interna In Dairy Calves. J Vet Intern Med 18(6): 907-910.

34. Stipkovits L, Ripley PH, Tenk M, Glávits R, Molnár T, Fodor L (2005): The Efficacy Of Valnemulin (Econor) In The Control Of Disease Caused By Experimental Infection Of Calves With Mycoplasma bovis. Res Vet Sci 78(3): 207-215.

35. Step DL, Kirkpatrick JG (2001) Mycoplasma Infection in Cattle I Pneumonia-Arthritis Syndrome. Bov Pract 35: 149-155.

36. Brown MH, Brightman AH, Fenwick BW, Rider MA (1998): Infectious Bovine Keratoconjunctivitis: A Review. J Vet Intern Med 12(4): 259266.
37. Levisohn S, Garazi S, Gerchman I, Brenner J (2004) Diagnosis Of A Mixed Mycoplasma Infection Associated With A Severe Outbreak Of Bovine Pinkeye In Young Calves. J Vet Diagn Invest 16(6): 579-581.

38. Kirby FD, Nicholas RA (1996) Isolation Of Mycoplasma bovis From Bullocks' Eyes. Vet Rec 138(22): 552-557.

39. Wustenberg M, Kirk J, Spencer H (2003) Mycoplasma: Calf To Cow In: Proceedings of $6^{\text {th }}$ Western Dairy Management Conference, Reno, Nevada, USA, pp. 166.

40. Sachse K, Pfutzner H, Heller M, Hanel I (1993) Inhibition of Mycoplasma bovis Cytadherence by a Monoclonal Antibody and Various CarboHydrate Substances. Vet Microbiol 36(3-4): 307-316.

41. Ayling RD, Gosney F, Hlusek M (2015) Mycoplasma Diagnostics, Some Results, And What We Still Don't Know About Mycoplasma bovis Disease. Cattle Prac 23: 248-251.

42. Stipkovits L, Rády M, Glávits R (1993) Mycoplasmal Arthritis And Meningitis In Calves. Acta Vet Hung 41(1-2): 73-88.

43. Sulyok KM, Kreizinger Z, Fekete L, Hrivnák V, Magyar T, et al. (2014) Antibiotic Susceptibility Profiles Of Mycoplasma bovis Strains Isolated From Cattle In Hungary, Central Europe. BMC Vet Res 10: 256.

44. Jensen L (2015) Outbreak Characteristics and Identification of Risk Factors For Mycoplasma bovis Danish Dairy Herds 2010-2014 Master Thesis, University of Copenhagen, Denmark Pp: 78.

45. Adegboye DS, Halbur PG, Nutsch RG, Kadlec RG, Rosenbusch RF (1996) Mycoplasma bovis-Associated Pneumonia And Arthritis Complicated With Pyogranulomatous Tenosynovitis In Calves. J Am Vet Med Assoc 209(3): 647-649.

46. Federal Ministry Of Agriculture (FMA) (2016) Livestock Census Official Files (Veterinary Statistics) Federal Department Of Livestock And Pest Control Services, Federal Ministry Of Agriculture And Rural Development, FCT, Abuja, Nigeria.

47. Egwu GO, Adamu M, Mshelia GD, Bukar-Kolo YM (2012) Isolates Of Mycoplasma Mycoides Subspecies Mycoides (Sc) In Small Ruminants In Sahel Zone Of Nigeria And Its Implications On Disease Control. African J Biotech 11(23): 6396-6401.

48. Nicholas RA, Ayling RD (2003) Mycoplasma bovis Disease, Diagnosis And Control. Res Vet Sci 74: 105-112.

49. Francis MI (2014) Isolation Of Mycoplasma bovis And Detection Of Its Antibodies In Cattle In Three Local Government Areas Of Adamawa State, Nigeria M.Sc Thesis, Ahmadu Bello University Zaria, Nigeria, Pp: $1-123$.

\section{Your next submission with Juniper Publishers} will reach you the below assets

- Quality Editorial service

- Swift Peer Review

- Reprints availability

- E-prints Service

- Manuscript Podcast for convenient understanding

- Global attainment for your research

- Manuscript accessibility in different formats ( Pdf, E-pub, Full Text, Audio)

- Unceasing customer service

Track the below URL for one-step submission https://juniperpublishers.com/online-submission.php 